УДК $130: 2$

DOI 10.52575/2712-746X-2021-46-4-679-688

\title{
Свобода и автономия личности: к вопросу о приватном пространстве
}

\author{
Чеснокова Л.В. \\ Омский государственный университет им. Ф. М. Достоевского, \\ Россия, 644077, г. Омск, пр. Мира 55a \\ E-mail: L. Tchesnokova@mail.ru
}

\begin{abstract}
Аннотация. Рассмотрены свобода и автономия личности в связи с правом на приватное пространство, возникшее в европейских обществах Нового времени. Условием существования приватности является наличие автономного индивида и общества, признающего за ним право на физическую и психологическую неприкосновенность. Возможность принимать автономные решения противоречит установкам патернализма, согласно которым можно вмешиваться в решения индивида ради его блага. Забота об индивиде по-разному оценивается в различных культурных контекстах. В обществах, где в качестве приоритета выступает уважение к свободе и неприкосновенности личности, она может восприниматься как вмешательство в приватную сферу человека и унижение его достоинства. Предпочтительным в публичной сфере является соблюдение социальной дистанции, что дает индивиду возможность самостоятельно делать выбор и нести за него ответственность.
\end{abstract}

Ключевые слова: приватность, публичность, автономия, патернализм, забота, социальная дистанция.

Для цитирования: Чеснокова Л.В. 2021. Свобода и автономия личности: к вопросу о приватном пространстве. NOMOTHETIKA: Философия. Социология. Право, 46(4): 679-688. DOI: 10.52575/2712-746X-2021-46-4-679-688

\section{Liberty and Individual Autonomy: To the Question of Private Space}

\author{
Lesya V. Chesnokova \\ Dostoevsky Omsk State University, \\ 55a Mira pr., Omsk 644077, Russia \\ E-mail: L. Tchesnokova@mail.ru
}

\begin{abstract}
The article examines freedom and autonomy of the individual in connection with the right to private space, which arose in European societies of the New Age in connection with the processes of urbanization and individualization. The condition of the existence of privacy is the presence of an autonomous, in need of own physical and mental space of the individual and society, recognizing his right to his physical and psychological integrity and autonomy as the right to make their own decisions regarding their own lives. The ability to make such decisions runs counter to the attitudes of paternalism, according to which it is possible to interfere with the decisions of the individual if it is supposed to be for his benefit. Caring for an individual is assessed differently in different cultural contexts. In societies where respect for freedom and the dignity of the individual is a priority, it can be perceived as interfering with and degrading the private sphere. The preferred social distance in the public sphere is to give a person the freedom and the opportunity to make his own choices and be responsible for him. The right to private space implies that everyone can determine his own destiny and autonomous in their decisions.
\end{abstract}

Keywords: privacy, publicity, autonomy, paternalism, care, civility. 
For citation: Chesnokova L.V. 2021. Liberty and Individual Autonomy: To the Question of Private Space. NOMOTHETIKA: Philosophy. Sociology. Law, 46(4): 679-688 (in Russian). DOI: 10.52575/2712-746X-2021-46-4-679-688

\section{Введение}

В настоящее время в отечественных и зарубежных исследованиях все большее внимание уделяется изучению приватности, которая является предметом, вызывающим интерес представителей самых разных дисциплин: философии, истории, культурологии, социологии. Считается, что уважение к приватному пространству является важным признаком современного демократического общества, основывающегося на признании прав и свобод человека.

Приватность (от латинского privare - отделенный, privatum - собственное) означает «области и сферы, которые заключены для себя, то есть не являются открытыми для общества. В контексте личности приватное относится не к общественному, а только к отдельной персоне или ограниченной группе лиц, находящихся в тесных или доверительных отношениях друг к другу» [Кравченко, 2001]. Смысл слова «приватность» связан со значениями таких понятий, как «право на личную собственность», «личное дело», «частная жизнь», и восходит к опыту «разделения физической и социальной среды, к контролю над собственной жизнью, к ответственности за совершаемый выбор» [Евстифеева и др., 2016, с. 36].

Современное разделение публичной и приватной сфер жизни не является чем-то, изначально свойственным человеческому обществу, это следствие сложных социокультурных процессов, получивших развитие в западных обществах Нового времени в результате процессов индустриализации, урбанизации, развития капиталистических отношений.

Ю. Хабермас проанализировал процессы возникновения публичной и приватной сфер в жизни человека и общества в своей ранней работе «Структурные изменения публичности», положившей начало научным дискуссиям об образе гражданина как носителя рациональности и индивидуализма, стремящегося к участию в публичной жизни. Одновременно с публичной сферой в буржуазном обществе формируется четко отграниченная от нее и защищенная законами и общественными нормами сфера приватного, где гражданин может отдыхать и общаться в узком семейном и дружеском кругу. «Буржуазия либеральной эры проживала свою приватность в семье. Областью приватной сферы был освобожденный от экономических функций «дом» [Habermas, 2015, p. 238]. Разделение между публичной и приватной сферами и защита от вмешательства в последнюю со стороны государства и общества - основополагающий признак современных демократических обществ, декларирующих защиту прав и свобод человека, частной собственности и невмешательства в личную жизнь граждан.

\section{Приватность, свобода и автономия}

Приватность неразрывно связана с такими понятиями, как свобода и автономия личности. С одной стороны, приватность существует только тогда, когда в ней есть потребность со стороны автономного, ощущающего себя отличающимся от других и нуждающегося в собственном физическом и ментальном пространстве индивида. По мнению Дж. Реймана, право на приватность - это не только право на личность и собственность. Оно является более фундаментальным и представляет собой «существование социальной практики, которая делает возможной для меня мысль о том, что это существование - мое. Это значит, что есть право на условия, необходимые для меня, чтобы думать о себе как о существе, имеющем права личности и собственности» [Reiman, 2007, p. 313]. Право на приватность приписывается индивиду, который «осознает, что обладает своей физической и ментальной реальностью» [Reiman, 2007, 317] и способен самостоятельно выбирать соб- 
ственную судьбу. Приватное - это область, в которой создается субъектность личности. Право на приватность дает индивиду возможность автономно прожить свою жизнь.

С другой стороны, автономия и свобода личности возможны лишь в обществе, признающем право индивида на неприкосновенное приватное пространство. Б. Рёслер полагает, что автономия возможна только тогда, когда субъекту предоставлено пространство, в котором он может принимать решения и рефлексировать над своими собственными действиями, чувствами и опытами без вмешательства извне. Она понимает приватность как «защиту от нежелательного доступа других, будь то физический доступ (в помещения) или метафизический (доступ к информации или попытки вмешательства в поведение других)» [Rössler 2001, p. 84]. Приватность неразрывно связана с автономией и свободой личности. Право на приватность предполагает, что субъект имеет право принимать решения, которые он не обязан каким-то образом легитимировать или объяснять. Только в исключительных случаях приватность может быть ограничена в качестве наказания за совершенные преступления.

Свобода связана с автономией, которая обозначает «способность самому для себя устанавливать законы, согласно которым действовать и которые считать правильными» [Rössler, 2018, p. 31]. Мы только тогда свободны в нашем выборе, когда сами являемся теми, кто сделал этот выбор без давления, манипуляций, насилия. Автономия предполагает возможность самостоятельно и осознанно осуществлять личные жизненные проекты: выбор профессии, создание семьи, поддержание дружеских отношений, наличие политических или религиозных взглядов и т.п. Автономия дает возможность самостоятельно делать выбор и нести за него ответственность.

Как отмечает Реслер, автономия предполагает постоянную проверку того, насколько собственная жизнь является следствием своего выбора, своей собственной жизнью. «Только автономно прожитая жизнь может считаться удавшейся жизнью» [Rössler, 2001, p. 96]. Ядро этой свободы состоит в том, чтобы принимать решения, исходя из собственной воли. Следовательно, «приватность связана с субстанциализацией прав на свободу. Она означает защиту от чужого воздействия, от гетерономии, дает возможность каждому индивиду строить свою собственную судьбу на основании собственных решений» [Böhme, 2018, p. 17].

\section{Право на приватность как результат общественных конвенций}

Право на существование приватности и автономии личности связано с обществом. «Права личности и собственности предполагают индивида, обладающего правом над собственным существованием. Общественное уважение к приватности обеспечивает эти права» [Чеснокова, 2020, с. 20]. Когда мы говорим об автономии индивидуальной личности, речь всегда идет о личности в социальных отношениях. Вне общества право на приватность не имеет смысла. Для ее существования необходимы социальные нормы, поддерживающие претензии индивида на приватное пространство. «Социальные нормы не только защищают и делают возможным определенное социальное поведение личности, они также требуют определенного поведения от индивидов и институтов, которые должны уважать приватность» [Rössler, 2018, p. 295]. Защита приватности необходима для возможности реализации определенных прав и свобод индивида в социальном пространстве, то есть для того, чтобы его планы и поступки в том случае, если они не нарушают ничьих интересов, могли быть реализованы без нежелательного вмешательства других.

Для защиты приватности необходимы конвенции, общественные договоренности. Формальных юридических прав недостаточно, чтобы создавать действующие социальные контексты для приватности, под защитой которых возможна самостоятельная жизнь. Уважение к приватности предполагает существование границ для вмешательства в жизнь индивида, которое препятствует индивидуальному образу жизни и поведения. Свобода 
решений насчет собственной жизни дает людям возможность контролировать степень вмешательства других благодаря существующим общественным нормам, позволяющим индивиду вести самоопределяемую жизнь и защищать свои личные границы. Меры для защиты своей приватности будут действовать только тогда, когда в обществе существует терпимость к чужим решениям, мнениям и мировоззрению.

В социальном общении требуются такие качества, как тактичность, невмешательство и сдержанность как уважение к приватным аспектам жизни индивида. Это может означать запрет для других комментировать, интерпретировать или влиять на его жизнь. Степень допустимого вмешательства зависит от социального контекста. Хотя, конечно, существует разная степень допустимости вмешательства в приватное пространство в зависимости от вида социальных отношений: от любви и заботы по отношению к членам семьи до нейтральной вежливости и индифферентности по отношению к чужим людям, но основополагающее право на уважение к приватности признается в современном обществе.

В настоящее время принято соблюдать определенную степень дистанции по отношению к другим людям, уважать их право на сокрытие личной информации. В противном случае происходит вторжение в приватную сферу индивида, что воспринимается как навязчивость, недостаток такта и воспитания. В этом случае индивид вынужден отстаивать границы своего приватного пространства от вмешательства со стороны «озабоченных родителей, недоверчивых родственников и любопытных соседей, самозванных блюстителей нравственности, непрошенных учителей и вахтеров. Все они нарушают право индивида «быть оставленным в покое» [Sofsky, 2007, p. 37]. Свобода одного заканчивается там, где начинается свобода другого. Приватность - это социальная практика, содержащая в себе сознательный отказ от вмешательства в дела других людей.

\section{Приватность и патернализм}

Возможность самостоятельно определять собственную жизнь часто вступает в противоречие с установками патернализма. Патернализм представляет собой попытки решать что-то за другого, если мы полагаем, что действуем в его интересах, подобно тому, как родители действуют по отношению к ребенку. Однако правом любого взрослого дееспособного человека является возможность самостоятельно делать выбор и нести за него ответственность.

Об этом говорится в трактате Дж. Милля «О свободе», который также называют «философским манифестом приватности». По мнению Милля, человек сам в состоянии делать выбор касательно собственной жизни, так как он сам лучше знает, чего он хочет. «Если только человек имеет хотя бы самую посредственную долю здравого смысла и опыта, то тот образ жизни, который он сам для себя изберет, и будет лучший, не потому чтобы быть лучше сам по себе, а потому, что он есть его собственный» [Милль 2000, c. 44]. Никто не вправе препятствовать взрослому человеку распоряжаться жизнью по собственному усмотрению. Он заинтересован в благе для себя гораздо больше, чем окружающие, и лучше всех знает, что именно является для него благом. Вмешательство окружающих в дела индивида основывается только на предположениях, которые могут оказаться ошибочными и быть применены некстати. Никто не знает всех жизненных обстоятельств другого человека.

Милль полагает, что в отношениях с другими лицами необходимо соблюдать принятые в обществе законы и правила, но в том, что касается его самого, индивид должен быть автономен. Он есть «высший судья того, что и как ему делать, и если он поступит вопреки всем советам и предостережениям и через это сделает сам себе вред, то этот вред далеко не может быть так велик, как велико было бы то зло, если бы он насильно принужден был поступить так, как другие признают для него благом» [Милль, 2000, с. 50]. Па- 
тернализм базируется на заблуждении, что люди не в состоянии самостоятельно позаботиться о себе.

Право на приватность опирается на социальные нормы, предполагающие для человека возможность сказать «это мое личное дело», чтобы дать понять, что чье-то вмешательство будет нежелательным. Однако западные нормы приватности приняты не повсеместно. Если рассматривать различные культуры с точки зрения их отношения к приватности, можно отметить, что там существуют различные варианты поведения по отношению к возможности вмешиваться в личные дела других.

\section{Приватность и забота}

Исследователи разделяют позитивное и негативное право на свободу, с которыми связаны различные формы уважения приватного пространства. С негативным правом связывается такое поведение, как сдержанность или сдержанное уважение, а с позитивным правом - забота. Как сдержанность, так и забота по-разному воспринимаются в разных культурных контекстах. Очевидно, что человеку, который находится в опасной или тяжелой ситуации и просит о помощи, в любом случае необходимо оказать поддержку. Однако вопрос вызывает то, насколько далеко может простираться необходимость проявления помощи и заботы в менее затруднительных ситуациях. «Забота в культурном контексте, требующем сдержанного уважения от окружающих и собственной ответственности от индивида, может быть воспринята как отсутствие уважения. И, наоборот, определенные формы сдержанного уважения в контексте этики заботы, могут казаться безнравственными» [Lotter, 2016, p. 187].

Например, в контексте современных западных либеральных обществ, провозглашающих в качестве основных ценностей свободу индивида и уважение к его правам, требуется не вмешиваться в его приватную сферу, поскольку считается, что взрослый дееспособный человек сам может о себе позаботиться. Порой забота может быть воспринята как унижение, в особенности, когда она открывает чью-то физическую слабость (так, например, в общественном транспорте в европейских странах не всегда принято уступать место пожилым людям, поскольку это может быть воспринято как публичное указание на их физическую немощность). Это не является проявлением бессердечия и равнодушия, а, напротив, является проявлением заботы, призванной пощадить самолюбие другого человека.

Подобное поведение можно обозначить как «симметричное уважение», характерное для эгалитарных обществ, стремящееся избавить человека от любой формы зависимости и вмешательства в его дела. Забота заключается в том, что мы «чувствуем себя ответственными за другую личность и что-то делаем для нее или имеем влияние на ее действия. Забота устанавливает определенную ассиметрию в социальных отношениях, определяемую различной способностью к действию» [Lotter, 2016, p. 194].

Однако в контексте мировоззрения традиционного общества, принятие действий, связанных с заботой, не воспринимается как удар по чувству собственного достоинства. Поскольку там никто не воспринимается как самостоятельная, аутентичная личность, а все являются так или иначе зависимыми друг от друга, забота воспринимается как «элемент цепи, в которой каждый выступает и в роли берущего, и в роли дающего. В подобном контексте сдержанность в проявлениях заботы и возложение на индивида ответственности за самого себя воспринимаются как эгоизм и нежелание помогать» [Lotter 2016, p. 194], а не как уважение к чужому приватному пространству. Тем самым человек выступает против обычаев и традиций, отказываясь выполнять свои обязанности в рамках социальной системы, в которой каждый зависит от участия и поддержки других.

Следовательно, исходя из теории культурного релятивизма, проявление заботы в одних культурных контекстах представляется проявлением внимания и уважения, а в других, напротив, кажется оскорбительным вмешательством. Нормы и границы приватности 
подвижны во времени и пространстве. В различных культурах, социальных слоях и поколениях существуют свои представления о границах приватности. Когда они не совпадают, возникает почва для конфликта.

\section{Приватность и civility}

Отношение к приватности, степень уважения к ней, зависящая от принятых в той или иной культуре социальных норм, формируется в процессе социализации. Потребность в социальной дистанции, тактичности, невмешательстве в дела других людей получила свое развитие в западноевропейских обществах в эпоху Нового времени. Особая сдержанность и вежливое невнимание присутствуют в современной городской жизни, чтобы поддерживать необходимую для совместного сосуществования большого количества людей дистанцию.

Г. Зиммель развивает идею о необходимости сдержанности для совместного проживания в современном большом городе. Отношения жителей крупных городов характеризуются замкнутостью, порой производящей впечатление холодности и отчужденности. Это вызвано психологическими причинами, поскольку «если бы непрерывным сношениям с бесчисленным множеством людей должно было бы соответствовать так же много внутренних реакций, как в маленьком городе, где знаешь почти каждого встречного, внутренний мир распался бы на атомы, и душевное состояние стало бы невозможным» [Зиммель 2002]. Сдержанность и самообладание требуются в тесноте большого города, вынуждающего человека соблюдать дистанцию в своих социальных контактах. Как отмечает Г.В. Горнова, в городском обществе существует особая потребность в приватном пространстве, которое «выполняет рекреационную функцию, в нем горожанин восстанавливает свои физические и психические ресурсы, освобождается от воздействия когнитивной перегрузки стимулами публичного пространства» [Горнова, 2014, с. 194].

Характеристикой современных либеральных обществ является поведение в социальном общении чужих друг другу людей, которое можно обозначить как civility (социальная дистанция). Элемент сдержанности по отношению к другим является необходимостью во всех социальных отношениях на основании плюрализма стилей жизни. Эта форма социальной дистанции не только простое проявление вежливости: «ее смысл состоит в том, чтобы индивидам предоставлялась та форма символического свободного пространства, в котором могла бы быть прожита самостоятельная жизнь, свободная от коллективных вмешательств» [Rössler, 2001, p. 158].

В результате подобного социального дистанцирования в современных обществах возможно мирное сосуществование самых разных индивидов. Уважение к личным границам предполагает невмешательство в дела и образ жизни других людей. Согласно нормам общения современного общества, индивиды, которые ведут себя, не соблюдая необходимой в данном социальном контексте дистанции, нарушают приватное пространство других, поскольку те вынуждены сталкиваться с чужими проблемами, с которыми они не хотят иметь дела. Напротив, сдержанность и невмешательство в чужие дела позволяют предотвращать потенциальные конфликты.

Социальные конвенции дают нам знать, что следует считать приватным, а что публичным пространством, в котором мы должны уважать личные границы других людей, выбирать вежливые нейтральные темы для разговоров, не вмешиваться в чужие дела и не выступать с излишней и неуместной откровенностью. При общении с чужими людьми необходимо придерживаться сдержанной толерантности, независимо от того какие эмоции вызывает их вид или поведение, если они не нарушают личного пространства. Грубыми и неуместными может выглядеть не только осуждение, но и непрошенные комплименты, которые также способны нарушить приватное пространство индивида. Приват- 
ность действует в обе стороны: защищает приватность индивида от других и защищает других от приватности индивида.

Публичность и приватность нарушаются, когда индивид ведет себя в соответствии с логикой другого пространства. Как отмечает В.О. Волковинська [2014] различие между публичной и приватной сферами заключается в отсутствии или наличии личного отношения к ситуации. В публичной сфере человек выходит из эмоциональных личностных отношений и в своем поведении руководствуется требованиями своей социальной роли. В том случае, когда во взаимодействии с чужими людьми индивид ведет себя согласно правилам общения в приватной сфере, это не соответствует нормам общения в публичном пространстве. В таком случае происходит следующее: «перенесение внимания с действий других на свои личные особенности, оценка событий и явлений по признаку «нравится / не нравится», чрезмерная сосредоточенность на собственных эмоциях и самопрезентации. Именно эту логику близких отношений индивиды обычно приносят в свою повседневную деятельность и взаимодействие с людьми, которые не являются близкими. И поэтому такую деятельность уже нельзя назвать публичной» [Волковинська 2014, с. 184]. Это разрушает социальное взаимодействие в публичном пространстве, в котором все должны вести себя согласно принятым на себя социальным ролям, а не в соответствии с правилами приватной сферы (например, когда продавец в магазине делает замечание или комплимент по поводу внешности покупательницы, не осознавая неуместность подобных высказываний).

Разделение поведения, принятого в публичной и приватной сферах свойственно, прежде всего, для западных обществ, начиная с эпохи Нового времени, характеризующегося развитием индивидуального начала. «Право на неприкосновенность приватной жизни каждого человека стало доступно по историческим меркам совсем недавно - вместе с развитием технологического, экономического, политического и культурного состояния общества» [Чеснокова, 2019, с. 378]. Вместе с развитием индивидуализма постепенно растет потребность в защищенном от вмешательства других людей физическом и ментальном пространстве. Чем выше уровень индивидуализма, тем более значимой представляется приватная сфера. В обществах Нового времени «человек становится свободно действующим существом, ориентированной на нравственность самостоятельной личностью» [Prentki, 2016, p. 8]. Развитие личности, рост индивидуализма предполагают индивидуальную ответственность за свою судьбу. Человек более не безмолвная часть целого, как в традиционном обществе, а единственная причина своих действий, он принимает решения и несет за них ответственность.

Однако, как отмечают исследователи, в подобном положении вещей кроются и достоинства, и недостатки. Необходимость делать самостоятельный выбор, принимать решения, нести за них ответственность зачастую вызывает тревогу и неуверенность. Из процесса индивидуализации проистекает тревога и нервозность. Поскольку в эпоху Нового времени «индивид покинул уютный мир заданных социальных порядков, то это означает, что за счет секулярных тенденций он попал в тревожный новый мир ненадежных норм, где нет постоянного распределения социальных ролей, где нужно обо всем заботиться самому и нести собственную ответственность» [Радкау, 2017, с. 27]. Современный человек постоянно сомневается: правильный ли он сделал выбор, будь то профессия, партнер или образ жизни, и соответствует ли он требованиям общества.

Структурные изменения, произошедшие в эпоху Нового времени, наряду со свободой, принесли также новые формы несвободы, связанные с избыточными требованиями и перегрузкой. Современный субъект ощущает себя вырванным из социальных связей традиционного общества, которые не только дискриминировали и подавляли, но также давали уверенность, защиту и жизненные ориентиры. Безмерно возросшее количество возможностей возникло наряду с недостатком социальных сдерживающих факторов. Предоставленный сам себе современный индивид сталкивается с постоянно растущей сложностью мира и 
требований общества без четких ориентиров и контроля. Поэтому «приватная автономия может как прекрасно удаваться, так и ужасно не удаваться» [Pollman, 2019, p. 167].

Иными словами, современность дает индивиду возможности, которые многими используются как освобождающие возможности, однако некоторыми - как эрозия социальных структур, угрожающая потерей личностной интеграции. «Растущий дефицит долгосрочных социальных связей приводит к неспособности создавать стабильные отношения. В результате многие современные субъекты чувствуют себя все более оккупированными чуждыми силами. Собственная самость теряет контуры. Угрожает ослабнуть создающая идентичность демаркационная линия между Я как Я и Я как другой» [Pollman, 2019, p. 169].

Таким образом, помимо невиданно расширившихся возможностей процесс индивидуализации, повлиявший на автономию и приватность, несет в себе и значительные издержки для индивида. К ним можно отнести такие опасности, как лишение ориентиров, границ, социальных связей, сдерживающих факторов. Необходимо быть достаточно зрелым, чтобы использовать преимущества права на приватность и автономию. В противном случае возможны процессы саморазрушения, которые никто не остановит, как это произошло бы в традиционном обществе.

Приватность и автономия имеют амбивалентный характер: как нечто освобождающее и отчуждающее, эмансипирующее и репрессивное, полезное и вредное. Следовательно, «как и любая свобода, приватность не гарантирует нравственного добра. В ее тайнах прячутся порой своеобразные склонности. Предпочтения человека редко бывают ценными, добродетельными, благородными и прекрасными. Здесь путают свободу и мораль. Свобода - это не добродетель, но предпосылка все добродетелей... Приватность, как и свобода, - ценность, которую люди ценят ради ее самой. Она не средство к цели, но сама цель» [Sofsky, 2007, p. 41].

\section{Заключение}

Таким образом, право на приватность возникает в западных обществах Нового времени вместе с развитием городов и ростом влияния класса буржуазии, придававшего особое значение ценностям дома и семьи как области, отграниченной от публичной жизни, вдали тревог и принуждений внешнего мира. Потребность в наличии приватного (в физическом и ментальном смысле) пространства, куда его обладатель может самостоятельно контролировать доступ, развивается вместе с ростом индивидуализма и с признанием прав человека со стороны государства и общества. Приватность неразрывно связана со свободой и автономией личности, с ее возможностью самостоятельно принимать решения касательно собственной судьбы.

Возможность самостоятельно принимать решения и нести за них ответственность противоречит установкам патернализма, стремящегося принимать решения за индивида во имя его блага. Забота как помощь в затруднительном положении может по-разному оцениваться в разных культурных контекстах. В западных либеральных обществах забота иногда может восприниматься как вмешательство в приватную сферу индивида и как свидетельство ассимметричных отношений. По отношению к незнакомым людям в публичной сфере предпочтительнее вежливое невнимание и соблюдение социальной дистанции. С одной стороны, такие социальные нормы дают пространство для собственного выбора, но, с другой стороны, в подобном образе жизни имеются свои опасности, связанные с более слабыми, чем в традиционном обществе, социальными связями, отсутствием четких правил и ориентиров. Однако, несмотря на недостатки, возможность свободного выбора связана с человеческими правами и свободами. Приватность связана с реализацией прав на свободу и автономию. Она дает возможность индивиду строить собственную жизнь на основании собственного выбора. Право на приватность является гарантом автономии и неприкосновенности человеческого достоинства. 


\section{Список литературы}

1. Горнова Г.В. 2014. Философия города. М., Форум, 342 с.

2. Евстифеева Е.А., Майкова Э.Ю., Козлов А.Г. 2016. Приватность в эпоху вовлеченности. Власть, 1: 36-40.

3. Зиммель Г. 2002. Большие города и духовная жизнь. Логос, 3-4. URL: http://magazines.russ.ru/logos/2002/3/zim.html (дата обращения: 29 января 2021).

4. Кравченко И.И. 2001. Приватность. В кн.: Новая философская энциклопедия. М., Мысль. URL: http://dic.academic.ru/dic.nsf/enc_philosophy/8928/ (дата обращения 29 января 2021).

5. Милль Дж. 2000. О свободе. В кн.: Антология мировой либеральной мысли (І половины XX века). М., Прогресс-Традиция: 288-392.

6. Радкау Й. 2017. Эпоха нервозности. Германия от Бисмарка до Гитлера. Пер. с нем. Н. Штильмарк. Изд. дом ВШЭ, 552 с. (Radkau J. Zeitalter der Nervosität. Deutschland zwischen Bismark und Hitler. München, Carl Hanser Verlag, 1998, 551 s.).

7. Чеснокова Л. В. 2019. Индивидуализированное общество как социокультурный фундамент приватности. Идеи и идеалы, 11 (3): 375-389. DOI: 10.17212/2075-0862-2019-11.3.2375-389.

8. Чеснокова Л.В. 2020. Право на приватность в либеральной философии Нового времени. Гуманитарный вектор, 15(3): 33-42. DOI: 10.21209/1996-7853-2020-15-2-33-42.

9. Волковинська В.О. 2014. Публічне і приватне у феноменологічному пошуку смислу соціальності. Збірник наукових праць «Гілея: науковий вісник», 88: 182-185.

10. Böhme G. 2018. Eine Kultur der Privatheit. In: Kultur der Privatheit in der Netzgesellschaft. Hrsg. von G. Böhme, U. Gahlings. Bielefeld, Aisthesis: 17-28.

11. Gavison R. 2007. Privacy and the limits of law. In: Philosophical Dimensions for Privacy: An Anthology. Ed. by F. D. Schoeman. Cambridge, Cambridge University Press: 365-366.

12. Habermas J. 2015. Strukturwandel der Öffentlichkeit. Untersuchungen zu einer Kategorie der bürgerlichen Gesellschaft. Fr. a. M., Suhrkamp Verlag: 391 s.

13. Lotter M. 2016. Scham, Schuld, Verantwortung. Über die kulturellen Grundlagen der Moral. Berlin, Suhrkamp: 344 s.

14. Pollman A. 2019. Schmerz, lass` nach. Die körperliche Hülle als Schauplatz autodestruktiver Privatisierung. In: Die Grenzen des Privaten. Hrsg. von S. Seubert, P. Niessen. Baden-Baden, Nomos: $165-180$.

15. Prentki J. V. 2016. Die anthopologische Funktion der Privatheit. Norderstedt, GRIN: 10 s.

16. Reiman J. 2007. Privacy, Intimacy and Personhood. In: Philosophical Dimensions for Privacy: An Anthology. Ed. by F.D. Schoeman. Cambridge, Cambridge University Press: 300-317.

17. Ritter M. 2008. Die Dynamik von Privatheit und Öffentlichkeit in modernen Gesellschaften. Wiesbaden, VS Verlag für Sozialwissenschaften: $139 \mathrm{~s}$.

18. Rössler B. 2018. Autonomie. Ein Versuch über das gelungene Leben. Berlin, Suhrkamp: $442 \mathrm{~s}$.

19. Rössler B. 2001. Der Wert des Privaten. Fr. a. M. Suhrkamp, 2001: 379 s.

20. Sofsky W. 2007. Verteidigung des Privaten. Eine Streitschrift. München, Beck: 158 s.

\section{References}

1. Gornova G. V. 2014. Filosofiya goroda [Philosophy of city]. Moscow, Publ. Forum: 342 p.

2. Yevstifeeva E.A., Maikova E.Yu., Kozlov A.G. 2016. Privatnost' v epokhu vovlechennosti [Privacy in an era of engagement]. Vlast', 1: 36-40.

3. Simmel G. 2002. Bol`shie goroda i dukhovnaya zhizn` [Big cities and spiritual life]. Logos, 34. Available at: http://magazines.russ.ru/logos/2002/3/zim.html (accessed: 29 January 2021).

4. Kravtchenko I.I. 2001. Privatnost` [Privacy]. In: Novaya filosofskaya enziklopediya [New Philosophical Encyclopedia]. Moscow, Publ. Mysl`. Available at: http://dic.academic.ru/dic.nsf/enc_philosophy/8928/ (accessed: 29 January 2021).

5. Mill J. 2000. O svobode [On liberty]. In: Antologiya mirovoy liberal'noy mysli (pervoy poloviny XX veka) [Anthology of world liberal thought (I half of the XX century)]. Moscow, Publ. Progress-Traditsiya: 288-392. (in Russian).

6. Radkau J. 2017. Epokha nervoznosti. Germaniya ot Bismarka do Gitlera [The era of nervousness. Germany from Bismarck to Hitler]. Moscow, Publishing house Higher School of 
Economics, 551 p. (Radkau J. Zeitalter der Nervosität. Deutschland zwischen Bismark und Hitler. München, Carl Hanser Verlag, 1998) (in Germany)

7. Chesnokova L. V. 2019. Individualizirovannoye obschestvo kak sotsiokul turnyi fundament privatnosti [Individualized society as a socio-cultural foundation of privacy]. Ideas and ideals. 11 (3): 375-389.

8. Chesnokova L.V. 2020. Pravo na privatnost` $v$ liberal`noy filosofii Novogo vremeni [The right to privacy in the liberal philosophy of modern times]. Humanitarian vector, 15(3): 33-42.

9. Volkovinska V. O. 2014. Publichne i private u fenomenologichnomu poshuku smyslu sotsialnosti [Public and Private in the Phenomenological Search for the Meaning of Sociality]. Collection of scientific papers "Gilea: scientific bulletin", 88: 182-185 (in Ukrain)

10. Böhme G. 2018. Eine Kultur der Privatheit. In: Kultur der Privatheit in der Netzgesellschaft [A culture of privacy. In: Culture of Privacy in the Network Society]. Hrsg. von G. Boehme, U. Gahlings. Bielefeld, Aisthesis: 17-28 (in Germany)

11. Gavison R. 2007. Privacy and the Limits of Law. In: Philosophical Dimensions for Privacy: An Anthology. Ed. by F. D. Schoeman. Cambridge, Cambridge University Press: 365-366.

12. Habermas J. 2015. Strukturwandel der Öffentlichkeit. Untersuchungen zu einer Kategorie der bürgerlichen Gesellschaft [The Structural Transformation of the Public Sphere: An Inquiry into a Category of Bourgeois Society]. Fr. a. M., Suhrkamp Verlag: 391 p. (in Germany)

13. Lotter M. 2016. Scham, Schuld, Verantwortung. Über die kulturellen Grundlagen der Moral [Shame, Guilt, Responsibility. About the Cultural Foundations of Morality]. Berlin, Suhrkamp: 344 p. (in English)

14. Pollman A. 2019. Schmerz, lass` nach. Die körperliche Hülle als Schauplatz autodestruktiver Privatisierung. In: Die Grenzen des Privaten [Pain, Ease up. The Physical Shell as a Scene of Autodestructive Privatization. In: The Limits of the Private]. Hrsg. von S. Seubert, P. Niessen. Baden-Baden, Nomos: 165-180 (in Germany)

15. Prentki J.V. 2016. Die anthropologische Funktion der Privatheit [The Anthropological Function of Privacy]. Norderstedt, GRIN: 10 p. (in Germany)

16. Reiman J. 2007. Privacy, Intimacy and Personhood. In: Philosophical Dimensions for Privacy: An Anthology. Ed. by F. D. Schoeman. Cambridge, Cambridge University Press: 300-317 (in Germany)

17. Ritter M. 2008. Die Dynamik von Privatheit und Öffentlichkeit in modernen Gesellschaften [The Dynamics of Private and Public in Modern Societies]. Wiesbaden, VS Verlag für Sozialwissenschaften: 139 p. (in Germany)

18. Rössler B. 2018. Autonomie. Ein Versuch über das gelungene Leben [Autonomy. An Attempt about the Successful Life]. Berlin, Suhrkamp: 442 p. (in Germany)

19. Rössler B. 2001. Der Wert des Privaten [The Value of the Privacy]. Fr. a. M. Suhrkamp, 2001: 379 p. (in Germany)

20. Sofsky W. 2007. Verteidigung des Privaten. Eine Streitschrift [Defense of the Private. Polemical Notes]. München, Beck: 158 p. (in Germany)

Конфликт интересов: о потенциальном конфликте интересов не сообщалось. Conflict of interest: no potential conflict of interest related to this article was reported.

\section{ИНФОРМАЦИЯ ОБ АВТОРЕ}

Чеснокова Леся Владимировна, кандидат философских наук, старший преподаватель кафедры социологии Омского государственного университета им. Ф.М. Достоевского, г. Омск, Россия

\section{INFORMATION ABOUT THE AUTHOR}

Lesya V. Chesnokova, $\mathrm{PhD}$ in Philosophy, Associate Professor at the Department of Sociology, F.M. Dostoevsky Omsk State University, Omsk, Russia 